\title{
O DIÁLOGO INTERCULTURAL E A FORMAÇÃO INICIAL DOS PROFESSORES DE CIÊNCIAS COM ABORDAGENS NA ESTNOBIOLOGIA, NA HISTÓRIA E NA FILOSOFIA DAS CIÊNCIAS: O CASO UEFS
}

\author{
Camilla Ferreira Amorim ${ }^{1}$; Geilsa Costas Santos Baptista ${ }^{2}$ \\ 1. Bolsista PIBIC/FAPESB, Graduando em Licenciatura em Ciências Biológicas, Universidade Estadual de Feira de \\ Santana, e-mail: millamylla2@gmail.com \\ 2. Orientadora, Departamento de Educação, Universidade Estadual de Feira de Santana, e-mail: \\ geilsabaptista@gmail.com
}

PALAVRAS-CHAVE: Formação de Professores; Ensino de Ciências; Diálogo intercultural.

\section{INTRODUÇÃO}

Sabendo-se que uma das práticas formativas do trabalho docente é - ou pelo menos deveria ser - a sensibilidade sobre a diversidade cultural inerente dos estudantes, sua consideração dentro da sala de aula deveria ser uma prática corriqueira. Pimenta (2002) releva a importância da sensibilidade por parte dos professores, pois é por esta via que ele “... se dá conta da situação complexa do ensinar. A sensibilidade é uma forma de conhecimento: Sensibilidade da experiência é indagação teórica permanente (PIMENTA, 2002, p.18).

A diversidade de culturas presente nas salas de aula constitui importante instrumento para o ensino de ciências, na medida em que pode favorecer a compreensão dos conteúdos científicos por meio do diálogo entre a cultura da ciência e as culturas dos estudantes. Neste sentido, uma proposta diferenciada ao abordar os conteúdos em sala de aula seria o uso da linguagem da etnobiologia como uma forma de contextualizar o conhecimento cientifica no meio sociocultural do educando. Sabendo que é um campo interdisciplinar, a etnobiologia estuda as diversas relações que os seres humanos e suas culturas estabelecem com a natureza. A etnobiologia, “... é o estudo do papel da natureza no sistema de crenças e de adaptação do homem a determinados ambientes (POSEY, 1986, p. 15).

Um dos principais objetivos da etnobiologia é promover um embasamento teórico capaz de integrar diferentes ramos das ciências naturais e sociais em outros campos de conhecimento científico, servindo como um elo entre diferentes culturas na intenção de elucidar a compreensão e o respeito mútuo entre os membros desses grupos e seus diferentes saberes e práticas (ROSA e OREY, 2014). No campo de ensino de ciências, segundo Baptista (2015), a estnobiologia pode trazer preciosas contribuições, podendo facilitar a investigação e compreensão dos saberes tradicionais dos estudantes, o que certamente permitirá aos professores estabelecer o diálogo com a cultura desses sujeitos, encorajando-os à participação durante as aulas. Todavia, cumpre destacar, não apenas a estnobiologia pode contribuir para o diálogo nas aulas de ciências. Para Baptista (2010), a história e a filosofia da ciência podem contribuir para que os professores consigam delimitar a natureza da ciência, elucidando para os estudantes as inúmeras relações que podem existir entre os conhecimentos científicos e aqueles que são inerentes aos seus meios socioculturais, sejam elas de semelhanças e/ou de diferenças. 
No presente estudo são apresentados dados da pesquisa de iniciação científica da primeira autora cujo objetivo central foi identificar a presença, ou não, de abordagens que permitem a sensibilização dos professores para lidar com a diversidade cultural nos programas dos componentes curriculares (obrigatórios e optativos) dos cursos de licenciatura em Ciências Biológicas e Pedagogia desta universidade. Partimos da premissa de que a estnobiologia, a história e a filosofia das ciências podem contribuir para a sensibilização dos professores para lidar com a diversidade cultural nas salas de aula, por permitir-lhes reflexões que lhes conduzirão para a investigação e compreensão dos saberes culturais dos estudantes e, por conseguinte, para o diálogo intercultural no ensino (Baptista, 2015). O seguinte questionamento deu origem ao nosso estudo: - Os cursos Licenciatura em Ciências Biológicas e Pedagogia da UEFS possui entre os seus componentes curriculares abordagens que permitem a sensibilização dos futuros professores para o diálogo intercultural nas salas de aula?

\section{METODOLOGIA}

A abordagem aplicada foi de natureza qualitativa (ANDRE, 2000) e teve como primeira etapa um levantamento de dados bibliográficos que permitiram o aprofundamento teórico acerca da temática e amparo às discussões. De forma interligada, realizamos consultas aos programas dos componentes do currículo da Licenciatura em Ciências Biológicas e Pedagogia da UEFS para a identificação da presença, ou não, de abordagens que permitem a sensibilização dos futuros professores para lidar com a diversidade cultural presente nas salas de aular, isto é, da estnobiologia, da história e da filosofia das ciências, além de outros possíveis que estivessem, de alguma forma, relacionados. Para isto, elegemos palavras-chave e, com base nelas demos busca nas ementas, nos objetivos gerais e específicos desses programas. As palavras chaves foram as seguintes: diálogos, interculturalidade, diversidade cultural, multicultural, sociointeração, culturalmente sensível, etnobiologia, epistemologia, natureza da ciência e história da ciência, sociologia e antropologia.

Os dados foram analisados seguindo a análise de conteúdo e processo de categorização proposta por Bardin (2002). Assim, utilizamos o critério semântico para categorização dos dados, que abrangeram duas etapas: 1. Listagem, com isolamento das informações em unidades de registro e 2. Classificação, com a organização das informações dentro de determinados temas. A partir daí, buscamos diálogos com a literatura da área de ensino de ciências e da etnobiologia.

\section{RESULTADOS E DISCUSSÃO}

Licenciatura em Ciências Biológicas. Dos 134 programas dos componentes curriculares que integram este curso, apenas 4 apresentaram relações com as palavraschave buscadas, o que nos permitiu a geração de três categorias, conforme apresentadas abaixo:

Categoria 01: Pluralidade Cultural e Etnobiologia. No que tange ao componente curricular Etnobiologia A (BIO547), foi possível observar que apesar de fazer referência direta à etnobiologia, não apresenta uma abordagem explicita sobre as contribuições desta ciência para o ensino e formação e professores de Biologia indicada 
por Baptista (2015), limitando-se a um tratamento generalista das relações do homem com a natureza, associando reflexão ecológicas e abordagens culturais.

O componente curricular Pluralidade Cultural e Inclusão Escolar (EDU 345) traz explicitamente abordagens que contribuem para a formação inicial do futuro professor para lidar com a diversidade cultural, indagando, por exemplo, preconceitos e estereótipos. De igual forma, apresenta oportunidades para a realização de planejamentos didáticos que incluam os universos culturais daqueles que chegam às escolas. Isto significa dizer que o futuro professor poderá ser capaz de analisar criticamente as práticas pedagógicas, identificando como poderá atuar no ensino que considera as visões de natureza dos seus estudantes. Isto, preferencialmente, por meio de questionamentos das relações de poder envolvidas na construção dessa diversidade, o que colabora para a formação da cidadania e ação social responsável (MORTIMER \& SANTOS, 2001).

Categoria 02: Sociologia e Antropologia. O componente Aspectos Sociológicos e Antropológicos (CHF570) pode provocar no licenciando uma relação com as demais disciplinas pesquisadas, uma vez que trabalha com questões voltadas para a diversidade cultural, como desigualdades étnicas, de classe social e de gênero, os diversos conceitos sobre cultura, relativização cultural, etnocentrismo, entre outros. Traz engajado na sua ementa o tema etnocentrismo, importante para o licenciando, pois essa visão de mundo pode influenciar negativamente os sistemas de ensino e sua formação de professor, uma vez que toma um determinado grupo étnico como centro de tudo e todos, sendo os demais pensados e sentidos através de valores próprios (ROCHA, 1984).

Categoria 03: História e Filosofia da Ciência. Entendemos que o componente curricular Evolução do Pensamento Filosófico-Científico (CHF568) permite reflexões epistemológicas por parte do futuro professor de biologia, para que compreenda que ao longo dos tempos as ciências enfrentam transformações, podendo contribuir, assim, para a sua sensibilização no sentido compreender como o pensamento científico muda ao longo dos anos. Isto, certamente, poderá ajudar-lhe a compreender as características do trabalho científico e ensinar de forma adequada a isto (MATTHEWS, 1994).

Licenciatura em Pedagogia. Nesta, identificamos a existência de 65 programas dos componentes curriculares, porém, apenas 37 foram encontrados, faltando, assim, 28 programas que não existem na organização do curso, segundo informação obtida junto ao Departamento de Educação da UEFS. Dos 37 programas encontrados e analisados, apenas 1 apresentou relações com as palavras-chave elencadas, sendo possível, então, a geração de apenas uma categoria:

Categoria 01: Diversidade Cultural. O que está proposto no componente curricular Educação e diversidade cultural (EDU310) se articula com os PCNs (1997), visto que traz entre os seus objetivos discutir possibilidades de vincular as práticas pedagógicas às experiências que alunos e alunas carregam consigo durante seus encontros com o conhecimento escolar, além de permitir reflexões acerca dos conceitos de cultura, de práticas dominantes nas sociedades passadas e atuais. Isto certamente preparará o futuro professor de ciências das séries inicias para lidar com a diversidade cultural encontrada nas salas de aulas, considerando aí que as escolas são espaços onde 
transitam saberes e realidades, sendo, portanto, um espaço dinâmico e polissêmico desde os primeiros anos escolares e faixas etárias.

\section{CONSIDERAÇÕES FINAIS}

As licenciaturas em Biologia e Pedagogia da UEFS possuem nos programas dos seus componentes abordagens que permitem a sensibilização dos futuros professores para o diálogo intercultural entre os conhecimentos científicos ensinados e os saberes culturais dos estudantes, por explicitarem temáticas que contribuem para reflexões e discussões sobre questões de grande relevância, como desigualdades étnicas, etnocentrismo, variações conceituais, relativização cultural, cientificismo e suas consequências para o ensino, etc. Todavia, entendemos que somente estas abordagens não são suficientes para que ocorra a formação do professor de biologia na sua totalidade no que diz respeito ao ensino intercultural.

Propomos que estes cursos busquem alterar as ementas e objetivos presentes nos seus componentes que tratam da história e filosofia da ciência, da sociologia, da antropologia e da etnobiologia, no sentido de pontuar claramente a aproximação entre os aspectos teóricos trabalhados na universidade com as vivências das escolas da região e seus professores com relação à diversidade ética e cultural.

\section{REFERENCIAS}

ANDRÉ, M. E. D. A. A pesquisa no cotidiano escolar. In: FAZENDA, I. (Org.). Metodologia da pesquisa educacional. 6. ed. São Paulo: Cortez, 2000, p. 35-45.

BARDIN, L. Análise de Conteúdo. Tradução de Luís Antero Reto e Augusto Pinheiro. Lisboa: Edições 70, 2002.

BAPTISTA, G. C. S. Importância da demarcação de saberes no ensino de Ciências para sociedades tradicionais. Ciência \& Educação, v.16, n.3, 2010.

BAPTISTA, G. C. S. Um enfoque etnobiológico na formação do professor de ciências sensível à diversidade cultural: estudo de caso. Ciênc. Educ., Bauru, v. 21, n. 3, p. 585603, 2015.

BRASIL. Secretaria de Educação Fundamental. Parâmetros curriculares nacionais: pluralidade cultural, orientação sexual / Secretaria de Educação Fundamental. - Brasília : MEC/SEF, 1997. 164p.

MATTHEWS, M. R. História, filosofia e ensino de ciências: a tendência atual de reaproximação. In: Cadernos Catarinense de Ensino de Física, vol. 12, n0, 13, 1995, p. 164-214.

MORTIMER, E. F.; SANTOS, W. L. P. Tomada de decisão para ação social responsável no ensino de ciências. Ciência \& Educação, v.7, n.1, p.95-111, 2001.

PIMENTA, S. G. De Professores, Pesquisa e Didática. Campinas: Papirus, 2002.

POSEY, D. A. Etnobiologia: Teoria e Prática. Petrópolis: Ed. Vozes, 1986.

ROCHA, E. O que é etnocentrismo. Ed. Brasilienses, 1984.

ROSA, M. \& OREY, D. C. Aproximando diferentes campos de conhecimento em educação: a etnomatamática, a etnobiologia e etnoecologia. VIDYA, v. 34, n. 1, p. 114, jan./jun., 2014. 